\title{
Research on Improving the Effectiveness of Agent Incentive System in China's Insurance Companies
}

\author{
Shaoguang Wang ${ }^{1, a}$ and Xi Feng ${ }^{2, b}$ \\ ${ }^{1}$ Business College of Pingxiang Uinversity, 211 Pingan North Road, Pingxiang, Jiangxi, China \\ ${ }^{2}$ F Business College of Pingxiang Uinversity, 211 Pingan North Road, Pingxiang, Jiangxi, China \\ a19607663@qq.com, b172136542@qq.com
}

Keywords: Insurance agent; Incentive Mechanism; Effectiveness

\begin{abstract}
Over the past decade, insurance agents have been developing rapidly in China, which has brought vitality to China's insurance market. With the increasing contribution of insurance agents to insurance companies, it has also attracted more and more attention from the society to the incentives of insurance agents. Although our agent incentive mechanism has developed for decades, its defects are also very obvious. Based on the analysis of relevant research results at home and abroad and our insurance agent incentive situation, in order to find the defects of the existing incentive mechanism, to provide ideas for the improvement of insurance industry management.
\end{abstract}

\section{Introduction}

In recent years, the development trend of China's more benign, not only the size increased significantly, at the same time, in the service of national economic and social development has played an important role, has penetrated into all aspects of the economy and society in china. China has entered a new normal. Under this background, the insurance industry will continue to develop rapidly in the long term. The development of insurance industry is inseparable from the hard work of insurance agents. However, the inconsistent agent and insurance company goals often flow rate is high, a large part of the reason is that the incentive mechanism of the agent is not perfect enough, failed to fully stimulate the marketing staff enthusiasm and working enthusiasm. Therefore, to study the incentive mechanism of insurance agent, to explore how to improve the effectiveness of the incentive mechanism, has important significance for promoting the healthy development of the insurance industry.

\section{A summary of China's research on insurance agents}

Study on the domestic insurance agent, a lot of focus on the agent system, especially the reform of the system of the agent, the agent incentive mechanism research is not much. Study on China's insurance agency relationship before 2000 mainly based on qualitative analysis, most of the experience and system of foreign countries, the agency system in finance or in law as the basic theoretical research. Therefore, the incomplete incentive system can not play its full role. After 2000, the researchers will introduce the theory of one agent into the study of the agency relationship of insurance entrustment, and discuss the contractual arrangements of both sides under the conditions of symmetric and asymmetric information in our country, and get the principal-agent relationship between the two parties. At this time the incentive mechanism of the design has a certain theoretical meaning. Meaning and practical significance [1].

The research on the incentive mechanism of agent: Cao Xiaolin and Zhang Qinghong, using the 
principal-agent theory, analyzed the optimal incentive contract of life insurance agents, and obtained the Commission incentive problem for the risk averse agent of life insurance [2]. It is feasible to increase the proportion of the renewal Commission with the rate increasing grade commission system. Li Guanyi, Chen Yanan believes that the current life insurance agent incentive mechanism to effectively promote the life insurance agent business actively, but can not avoid short-term behavior caused by the high commission in the early time [3]. Bian Wenxia believes that the salary incentive for life insurance agents should not pay attention to the amount of business, but also emphasis on service quality, insurance agents are given to establish the evaluation system of personal credit, change agent commission payment mode [4]. It is suggested that measures should be taken to improve the management system of life insurance agents by increasing the opportunity cost and other related incentive mechanisms of life insurance agents' irregularities [5].

\section{Analysis of the reasons for the problems existing in the incentive mechanism of insurance agents in China}

\subsection{The current salary system is the root cause of the short term behavior of agents.}

At present, insurance companies in China generally pay premiums to the insurance agents as a larger proportion. The Commission of the insurance company is based on the combination of the first commission and the renewal Commission. The first period Commission is higher and the renewal Commission decreases year by year. This system itself has a "focus on short-term interest", which makes the agent pursue the high commission in the early stage and pay attention to the short-term behavior, regardless of the quality of service [6]. Volume and business reputation. The first year after the annual percentage decline, this arrangement makes the agent insecure about their income, and to contribute to the new single use unscrupulous divisive tactics, and the problems caused by the surrender, the staff's high turnover rate etc..

\subsection{High loss rate restricts the development of agents}

China's insurance companies mostly adopt the strategy of "sea of people", attracting large numbers of talents, and then eliminating them in large quantities. With the expansion of business scale of the insurance company, performance evaluation is becoming more and more strict, resulting in serious loss of insurance agent, which has become a prominent problem restricting the sustained and rapid development of the insurance company [7]. There are many reasons for the high loss rate. The unclear legal status of the agent is the important reason for the high rate of withdrawal, because the insurance agent is not the official employee of the insurance company, does not enjoy the welfare guarantee of the company, the work has no sense of belonging, and the two sides sign the "insurance contract". Under such circumstances, the insurance agent should face the pressure of life, the pressure of competition, and the protection of the lowest standard of living.

\subsection{Agent behavior oriented mechanism needs to be improved}

With the growth of China's insurance agency team, premium income has risen rapidly. The illegal phenomenon of insurance agents is increasing. Some agents use their information advantage, to promote or cause events, their benefit while the client is to bear all or part of the consequences of damage to the interests of. For the violation of agents, insurance companies should take some punishments. 


\section{Suggestions on enhancing the effectiveness of incentive mechanism for insurance agents}

Effective incentive for insurance agents, consideration must be given to the stage and the richness of the objectives, targeted to meet the needs of diverse agents, prompting them to consider more long-term interests of the insurer.

\subsection{Improving the current insurance agent training system}

Training is the insurance agent to get the growth momentum, the insurance business as a sustainable career incentives, the insurer should be trained as a long-term investment, to establish a suitable training management system. Combined with the personal career development of insurance agents, the participants and contents should be determined to meet the needs of individual career development. Linking training with agent's promotion and remuneration will enhance the initiative and enthusiasm of agent's learning [8].

\subsection{Establishing an individual credit evaluation system for insurance agents}

The increase in personal credit index agent insurance agent's performance evaluation, the establishment of historical work records for each agent, rating through these historical data integrity status of insurance agent. In formulating the proportion of commission payment, the agent's credit rating factors are taken into consideration and the corresponding commission payment ratio is formulated for different credit grades, so that the agent with high credit degree can get reasonable and generous remuneration, and the good reputation will inevitably attract more customers. Therefore, the agent will improve its self. The quality of your work to maintain long-term customer relationship.

\subsection{Introduction of fixed income}

The insurance company's agent in addition to gain or have access to fixed income amounts ranging from outside in the probation period, basically do not enjoy formal employees can enjoy the benefits, directly linked to salary and performance. This special salary structure is reasonable, but it is also the reason why the agent's income fluctuates greatly. The "sea tactics" makes the agent's behavior short-term. Some scholars have suggested that the incentive fixed income system should be implemented to set the standard of fixed income as the minimum living security level or the local average wage level, but this may bring the agent "laziness" and the real problem of the substantial increase in the cost of the insurer's sales.

\section{4 moderate increase of commission rate}

The current commission system, the insurance agent commission generally higher proportion of first year commission, the industry rules induce agent illegal operation of the quick action in a certain extent. If we reduce the payment rate of the first commission appropriately, change the structure of the commission payment and extend the payment period of the Commission, this will help to extend the career of the individual agent. With the passage of time, the agent of irregularities will be found easier to induce the agent to achieve long-term interests of commission have to pay attention to and pay attention to their own credit construction, increase their efforts on quality of service.

\section{Conclusion}

The incentive mechanism of insurance agents must be able to motivate employees from multiple 
angles and levels. This requires that the agent incentive mechanism should be set up from various aspects, including not only material, but also spiritual aspects, not only to meet the needs of low levels, but also to meet the satisfaction of high levels of demand; not only should the agent be encouraged to achieve the short term objectives of the organization, but also the long-term goal of the organization. Mark.

\section{References}

[1] Zhou Pin. Study on the incentive mechanism of insurance agents' moral hazard prevention [D]. Hunan University, 2015

[2] Cao Xiaolin, Zhang Qinghong. Based on the principal-agent theory, the incentive analysis of personal agent for life insurance [J]. East China economic management, 2013 (1)

[3] Jiang Yong. Optimal insurance contract model under the condition of moral hazard [J]. Journal of Industrial and Commercial University Of Chongqing Social Science Edition, 2013

[4] Sun Liming, sun Qi Xiang. Information asymmetry in the management of insurance agents [J]. Journal of Peking University, 2003

[5] Wang Guoying, analysis of organizational factors affecting the loss of insurance salesmen [J]. insurance research, 2007 (5)

[6] Peking University, China Insurance and social security research center. Comment on the hot topics of China's insurance market [M]. Beijing people's studies press, 2014

[7] Huang Yingjun, Fu Li Yao. Loss of insurance agents: [J]. insurance school, Southwestern University of Finance and Economics, 2016

[8] Pan Jin, Xu Jing. Insurance service marketing [M]. Shanghai University of Finance and Economics press, 2005 